\title{
A família Como instituição moderna
}

\author{
Danielle Marques dos Ramos \\ Virgílio Gomes do Nascimento ${ }^{\star}$
}

\begin{abstract}
Resumo
Toda instituição é uma ferramenta de socialização criada pelo próprio homem com a função de gerenciar suas relações interpessoais. A instituição normatiza, legaliza, legitimiza os comportamentos do indivíduo em sociedade. Ela também é geradora de estabilidade e segurança nas trocas sociais. Sendo a familia uma instituição, ela se apresenta como a primeira instituição com a qual o indivíduo tem contato em sua vida. Entretanto, as mudanças ocorridas na sociedade têm alterado as formas de interação social dentro das famílias, constituindo novos modos de relacionamento entre indivíduo e meio. Tais mudanças são importantes na ressignificação da família enquanto instituição social.
\end{abstract}

Palavras-chave: família; instituição; modernidade.

\section{FAMILY AS MODERN INSTITUTION}

\begin{abstract}
Every institution is a socialization tool created by man with function of managing your own interpersonal relationships. Institution creates norm, law, legitimacy for individual's behavior in society. It is also generator of stability and security in social exchanges. Considering family like an institution, it presents itself as the first institution with which individual has contact in life. However, changes occurred in the society have altered ways of social interaction inside the families, establishing new ways of relationship between individual and environment in and out of them. Such changes are important in the new signification of family while a social institution.
\end{abstract}

Keywords: family; institution; modernism.

\footnotetext{
^ Mestre em Psicologia Social pela Universidade do Estado do Rio de Janeiro, pós-graduada em Gestão de Recursos Humanos pela Universidade Candido Mendes, professora da Sociedade Educacional Fluminense - Rua Pracinha Wallace, Paes Leme, ${ }^{\circ}{ }^{1338}$, Nilópolis, Rio de Janeiro.

E-mail:dmelle.mr@gmail.com ou dmelle@oi.com.br

$\star \star$ Mestre em Sexologia pela Universidade Gama Filho, pós-graduado em Psicologia Hospitalar pela UNISA - Universidade de Santo Amaro - SP, com formação em Terapia Familiar pelo ITFRJ, e Terapia Cognitivo-Comportamental pelo CPAF-RJ, além disso, é professor da Sociedade Educacional Fluminense.

E-mail:vgnascimento@hotmail.com ou vgnascimento@oi.com.br
} 
Pode-se perceber em todas as sociedades humanas a presença das instituições como órgãos propagadores de normas e valores socialmente compartilhados (SOUTO, 1985). De fato, são as instituições que organizam e viabilizam a existência da sociedade (LOURAU, 1996).

A dificuldade de se conceituar instituição dentro da literatura específica é algo a ser destacado. Há uma grande diversidade sobre o entendimento do que é uma instituição, sendo esta descrita em termos excessivamente amplos (SOUTO, 1985) ou tão restritos que se confunde com outro conceito: o de organização (SCOTT, 1996).

A principal função de uma instituição é a propagação dos valores inscritos nela. Um dos processos que permitem essa transmissão de valores é a socialização, cujo objetivo traduz-se na divulgação das leis e normas institucionais facilitando a interiorização das mesmas pelos indivíduos.

Este trabalho tem por objetivo discorrer sobre as instituições, suas características e seus objetivos de uma forma mais geral, concatenando os saberes sobre esta temática e intentando traçar um perfil daquilo que é comum a todas as instituições.

Em seguida, será abordada a família como instituição, tendo em vista um foco sociológico da mesma. A família pós-moderna será posta em evidência ao se descreverem suas características e suas limitações dentro da sociedade atual, situando-a dentro de um contexto sócio-histórico da civilização ocidental.

\section{As instituições}

As instituições são encontradas em todas as sociedades (SOUTO, 1985). Mesmo que se considerem as diferenças entre os grupos sociais e, numa escala mais larga, a diversidade cultural existente entre os povos, as instituições ainda se fazem presentes como veículos normatizadores das atitudes, das opiniões, etc., sendo guias práticos para as ações dos indivíduos em suas relações sociais. Foi Hegel quem deu destaque às instituições colocando-as na posição de fundadoras da sociedade (LOURAU, 1996). Sem as instituições a vida social seria impossível, pois elas servem de fonte norteadora para o que é permitido ou não; são elas que limitam a ação do indivíduo dentro de um espectro em que a racionalidade seja valorizada; sem as instituições o ser humano viveria na natureza levado apenas por seus instintos mais básicos: sede, fome, sexo, descanso. Portanto, as instituições são criações humanas para regulação de seu convívio social, ou, nas palavras de Durkheim (apud SCOTT, 1996, p. 10), "são produtos da interação humana".

Dentro da Sociologia o conceito de instituição mostra-se um tanto difícil de se definir. Há distinções entre microinstituições - paternidade, maternidade, casamento, etc. - e macroinstituições - família, Igreja, Estado, etc. (SOUTO, 1985). Mas o que permeia todas essas micro e macroinstituições é a regulação, o roteiro de ação para a interação social entre os indivíduos. Sendo assim, a instituição pode ser definida como "um conjunto de normas que se aplicam num sistema social, e que definem o que é legítimo e o que não é nesse sistema" (SOUTO, 
1985, p. 211). Em outras palavras, instituições "são um sistema de normas que regulam as relações entre os indivíduos e que definem como estas relações devem ser" (SCOTT, 1996, p. 12).

Além dessa dificuldade em conceituar instituições, há também dificuldade em diferenciá-las das organizações (SCOTT, 1996). De fato, são conceitos muito próximos e muitas vezes tratados como sinônimos pela literatura. Uma diferença básica entre instituições e organizações refere-se ao nível de sistematização das regras e normas sociais; quanto mais sistematizadas, mais se aproximam do que é uma organização (ALBUQUERQUE, 1986).

Alguns autores vêem as organizações como algo mecânico, cujo objetivo principal é a realização de tarefas para se alcançar metas. As normas sociais criadas nesse meio são feitas apenas para otimizar a obtenção das metas planejadas. Outros as entendem como um sistema orgânico, de cunho adaptativo, que é afetado pelas características particulares de cada indivíduo e pelas pressões do meio (SCOTT, 1996). Mecânicas ou orgânicas, as organizações são expressões de grupos menores do que os observados pelas instituições, tendo objetivos mais claramente definidos que estas últimas.

Outra diferença entre instituições e organizações é o nível de estratificação. A existência de hierarquias representativas de poder é muito maior nas organizações do que nas instituições (SCOTT, 1996). É claro que dentro de uma instituição como a família, por exemplo, essa verticalidade é notada na posição ocupada pelo pai, pela mãe e pelos filhos. Contudo, nestas as diferenças de poder são naturalizadas e não se apresentam como socialmente construídas. Em uma empresa, o poder exercido pelos diretores está "escrito" nas normas de funcionamento da mesma; a hierarquização é produto dos indivíduos, não é natural; esta é abertamente definida. Isso se torna evidente quando um novo membro é aceito na organização. Este deve tomar ciência das regras organizacionais vigentes através de outros colegas mais antigos e passar a adotar os valores inscritos nessa organização (SCOTT, 1996).

Pode-se dizer que uma organização é menor do que uma instituição. Entretanto, se uma organização se mantém ao longo do tempo, ela pode se tornar uma instituição. A esse processo de transformação de uma organização em uma instituição chama-se institucionalização (SCOTT, 1996). Através da cognição as instituições têm suas bases fundadas na natureza e na razão. Ao naturalizar as classificações sociais, as instituições encontram a estabilidade necessária para seu surgimento e manutenção (DOUGLAS, 1998).

É de Emile Durkheim o enunciado de que o pensamento individual tem suas origens no pensamento social (DOUGLAS, 1998). Durkheim estudou a religião de povos primitivos, pois com isso ele acreditava poder estabelecer as regras universais para o comportamento. $\mathrm{O}$ que ele queria indicar é que o pensamento e o comportamento de um indivíduo são guiados pelas normas sociais cristalizadas e coletivamente partilhadas; em outras palavras, um indivíduo pensa segundo o estabelecido pelas instituições. Para ele, as instituições são sistemas simbólicos 
de conhecimento, crenças e autoridade moral (SCOTT, 1996). É através destes sistemas simbólicos coletivamente construídos que o mundo é explicado, alcançando-se estabilidade.

Durkheim, ao declarar que o pensamento individual tem suas bases no pensamento institucional, foi taxado pelo meio acadêmico de ser um racionalista radical (DOUGLAS, 1998). Mas, para ele, explicar o social pelo individual incorria em grande erro (SÁ, 1993). Outros estudiosos como Frederick Bartllet e Donald Campbell se juntaram a Durkheim na crítica à corrente psicológica de explicação do pensamento. Bartllet afirma pejorativamente que os psicólogos são incapazes de enxergar os seres humanos como seres sociais porque a "instituição" Psicologia não concebe o indivíduo como um ser socialmente guiado. Para reiterar essa idéia, Campbell fala da impossibilidade do psicólogo de conceber o desenvolvimento psíquico do indivíduo dentro de convenções sociais. Para este profissional, toda convenção social só pode ter reflexos negativos no indivíduo (DOUGLAS, 1998).

O que a Psicologia, na visão destes estudiosos, parecia não entender é que o indivíduo está inscrito em uma rede de instituições. De fato, o homem pertence a um grande número delas, umas distintas das outras (Igreja, Estado, Família), que guardam leis de relacionamento entre si. São estas leis que dão possibilidade ao indivíduo de se colocar dentro ou fora das instituições de acordo com suas escolhas (LOURAU, 1996).

O processo que descreve a relação entre o indivíduo e as instituições se chama interiorização. Em sua primeira fase há a incorporação: é quando os valores das instituições são interiorizados. Na segunda, há a personificação: é quando o indivíduo projeta para o meio os valores institucionais devidamente assimilados e incorporados de sorte a permanecerem originais e particularmente desenvolvidos (LOURAU, 1996). Essa é uma das grandes qualidades do pensamento institucional, tornar as instituições tão internalizadas que parecem inexistentes ou invisíveis (DOUGLAS, 1998).

Parece haver urna determinação mútua entre indivíduos e instituições. Enquanto estas pensam e dizem como os indivíduos devem pensar (DOUGLAS, 1998), aqueles modificam as formas de compreensão das instituições através de ressignificações. SCOTT $(1996$, p. 8) explanou isso muito bem quando declarou “[...] o individual é sempre causa e efeito da instituição”. LOURAU (1996) coloca o indivíduo como um ser instituído, não existindo antes da instituição nem fora dela, apenas nela, quer seja contra ou a favor. Toda resposta que for apresentada só parecerá correta quando apoiada no pensamento institucionalizado; o processo decisional está sempre pautado nas instituições, pois o indivíduo só existe na instituição e suas decisões são afetadas por ela. Desta forma, o indivíduo constrói sua própria visão de mundo e seus comportamentos e pensamentos são criados de sorte a sustentar esta visão e os padrões de interação social que ela suscita (DOUGLAS, 1998). 
Esses padrões de interação social são como regras moldadas pelas instituições. Tendo-se uma regra, sabe-se como agir e, conseqüentemente, tem-se uma idéia do que seria esperado da interação. As instituições comportam as expectativas futuras dos indivíduos em várias situações sociais; quanto mais expectativas uma instituição cobrir, maior será a sensação de segurança ante o mundo. Essa segurança tem como efeito no indivíduo o reforço no cumprimento de comportamentos que tendem a se conformar ao pensamento institucional (DOUGLAS, 1998).

A instituição apresenta características que lhe são particulares e que a constituem. A segurança ou estabilidade que fornece ao indivíduo são algumas das conseqüências do pensamento institucional, as quais guardam relações estreitas com as características definidoras da instituição. Berger, P. e Berger, B. (1978) elencam cinco fatores de importância na constituição das instituições sociais: (1) exterioridade: elas têm realidade externa ao indivíduo; isso significa que elas são experienciadas como algo que possui um "corpo físico", não são apenas entidades abstratas e internas e ao ser humano. Como exemplo, pode-se citar a família que é vista como algo concreto em seu "corpo" palpável, não apenas uma mentalização; (2) objetividade: elas são objetivas porque se constituem como uma realidade compartilhada por vários indivíduos e as formas percebidas pelos mesmos são muito semelhantes entre si; (3) coercitividade: elas têm poder sobre o indivíduo, são capazes de determinar quais comportamentos são aceitos segundo o conjunto de possibilidades que lhes determinam. É a coerção imposta pelas instituições que garante sua estabilidade e continuidade ao longo do tempo. Isso não significa que elas sejam imutáveis, e nem poderiam ser, visto resultarem das ações de vários indivíduos na construção de uma significação comum. A coerção se apresenta apenas como uma proteção ao caráter da instituição, não como um impeditivo de mudanças; (4) autoridade moral: não se mantêm somente pela coerção; elas falam de um lugar legitimado, suas ações são ações que implicam direitos. Em outras palavras, um indivíduo age e recebe recompensas ou punições de acordo com as leis institucionais que determinam se o comportamento do mesmo está de acordo com as normas ou foge aos padrões da instituição, e, (5) historicidade: elas são algo que existia antes do nascimento do indivíduo e vai continuar a existir depois dele. Elas são a soma de pensamentos de diversos indivíduos que interagem com elas ao longo de suas vidas.

Em Albuquerque (1986) as instituições são vistas como forma de dominação ideológica. Os indivíduos pensam e agem de acordo com a ideologia subjacente reinante nas instituições. Essa é uma forma de dominação muito cruel e eficaz; cruel porque deixa ao indivíduo a sensação de liberdade, de pensar por si, e, eficaz porque o coloca na posição de reprodutor voluntário da ideologia dominante. Isso reflete uma característica muito expressiva das instituições que é a de se tornar invisível.

A capacidade que o indivíduo tem de incorporar a ideologia institucional é tão grande que, protegido pelas regras legais da mesma, o indivíduo pode cometer atos que não cometeria se estivesse em outro contexto institucional. Esse anonimato de ações legitimamente exploradas é muito comum e reflexo de um 
pensar institucional internalizado acriticamente (SOUTO, 1986). A independência intelectual nesse contexto da instituição é quase uma utopia, mas que pode ser alcançada quando o indivíduo descobre como o controle ideológico lhe está sendo imposto (DOUGLAS, 1998).

Em uma visão mais próxima do marxismo têm-se as instituições como instrumentos de poder. Isto significa que elas são usadas para legitimar formas de dominação de classe - das classes dominantes sobre as dominadas - em que nem as primeiras nem as segundas têm consciência dos papéis exercidos, apenas reproduzem-nos perpetuando as diferenças (LOYOLA; QUINTEIRO, 1982).

Dar legalidade às ações sociais é uma das características da instituição. Pensar em agir legitimamente implica manter-se dentro das regras, assumindo corretamente os papéis sociais que são cabíveis ao indivíduo. A capacidade que uma instituição tem de legitimar um comportamento é tamanha que qualquer desvio é prontamente sancionado (LOYOLA; QUINTEIRO, 1982).

Um papel social é um guia prático para os comportamentos do indivíduo. Entende-se por papel "uma seqüência de práticas estruturadas e reconhecidas" (ALBUQUERQUE, 1982, p. 132). O papel social fornece as ações legitimadas institucionalmente e submete o indivíduo às punições quando este se afasta daquele. Ele gera expectativas de comportamento nos demais; quando um indivíduo cumpre com seu papel social, ele está ajudando a tornar a realidade mais estável na medida em que as interações com os outros são menos conflituosas. Papéis, rótulos e classificações são, portanto, estruturas que estabilizam o fluxo da vida social, além de perpetuar a ideologia da instituição e criar a realidade na qual são aplicados (DOUGLAS, 1998).

Atreladas ao papel social e a sua função de estabilidade interativa entre os indivíduos têm-se as normas sociais. O fato de muitas destas parecerem naturais indica que sua interiorização se deu ao longo da socialização de forma suave, tão suave e imperceptível como o são os saberes institucionalmente adquiridos (SOUTO, 1985). Normas sociais também ordenam a vida social dando previsibilidade para o mundo percebido pelo indivíduo.

Legitimidade, normas e papéis sociais são características das instituições que não estariam completamente explicadas sem a compreensão dos símbolos contidos neles. Uma instituição não se reduz a seus símbolos, mas também não pode viver sem eles (CASTORIADIS, 1982). Ela também é produtora de símbolos, os quais nutrirão a vida dos indivíduos sem que estes percebam. De fato, a sociedade se molda aos símbolos e estes são moldados por ela (LOURAU, 1996). O papel da bidirecionalidade aparece aqui como algo institucional.

Em resumo, a instituição é um processo de socialização criado pelo homem para regular seu convívio em sociedade. A internalização das normas, leis e papéis sociais confere à instituição o grau de naturalidade que se observa, dando legalidade às escolhas do indivíduo. 


\section{A instituição família}

Várias são as instituições sociais estudadas pela Sociologia. Instituições religiosas, políticas ou governamentais e econômicas são algumas das que determinam a sociabilidade humana (SOUTO, 1985). Além destas, a família também é entendida como uma instituição social. De fato, ela é a principal fonte de socialização do indivíduo ao ensinar-lhe quais os padrões e normas culturais adequados que devem ser internalizados e reproduzidos em suas relações sociais (LASCH, 1991).

A família proporciona a aprendizagem de normas sociais que conduzem à interação dos indivíduos dentro de suas paredes institucionais. Ela também fornece um manual prático dos comportamentos e pensamentos permitidos ou não ao indivíduo. Os papéis sociais são desde cedo distintamente assimilados pela criança. A percepção do que é ser pai, ser mãe, ser filho e/ou irmão vai se formando e determinando os modos de estar do infante ante ao mundo ao longo de sua infância (STEWART ; GLYNN, 1978).

A família dá legitimidade às normas e papéis sociais que a criança internalizará em seu crescimento. Ela é, talvez, a primeira instituição com a qual o indivíduo tem contato em sua vida e que serve de base para todas as outras (LASCH, 1991). Afinal, ela é quem torna o indivíduo um ser social e como tal imerso na cultura e valores coletivamente disseminados.

O simbólico está ricamente representado dentro da família. Desde o nascimento até o casamento, o homem vive diversos ritos de passagem cobertos de simbolismo. As representações divinizadas dos pais são um exemplo de como o simbólico é capaz de modificar e influenciar as ações, pensamentos e emoções dele diante do mundo que se lhe descortina.

As funções mais universais atribuídas à família correspondem a: (1) perpetuar a espécie humana; (2) cuidar dos mais velhos e inválidos; (3) dar nome e status (SOUTO, 1985); (4) socializar o indivíduo em relação aos padrões e normas sociais dominantes; (5) dar segurança (LASCH, 1991; LOURAU, 1996).

A instituição família apresentou grandes mudanças a partir do século XIX. O casamento, especialmente, foi o receptor da maioria destas transformações. Sai de cena a união por contrato, escolhida pelos pais dos cônjuges e tem lugar o casamento por amor e a escolha do parceiro pelos próprios indivíduos (ARAUJO, 2002). Com o advento do capitalismo e da industrialização, a família passou a representar um refúgio ante as ameaças do mundo (LASCH, 1991). Ela diminuiu em número de membros, tornou-se patriarcal, hierarquizada, com a divisão do trabalho sendo sexualmente definida e dicotomizada em público versus privado (VAITSMAN, 1994).

A então chamada família burguesa era basicamente construída pelo marido e pela mulher, o que fez com que também fosse denominada de família conjugal (STEWART; GLYNN, 1978). No estudo desta instituição, tornou-se tão impor- 
tante o destaque dado à conjugalidade que se chegou mesmo a utilizar o casal feliz como parâmetro para a avaliação do grau de felicidade dentro dela (LASCH, 1991; STEWART; GLYNN, 1978).

A família burguesa (ou moderna) dava ao homem o papel de provedor, responsável por sua manutenção e sustento. À mulher cabia o papel de educadora dos filhos, gerente do lar e da privacidade. O homem era a figura pública, aquele que trabalhava fora, lidava com o mundo externo. A mulher era o privado, a zeladora do bem-estar do marido e dos filhos, a defensora da intimidade familiar. Esta instituição era tipicamente patriarcal (VAITSMAN, 1994).

Entretanto, essa estrutura familiar não corresponde ao observado atualmente. Tendo em vista as taxas crescentes de divórcio que, segundo Féres-Carneiro (2003), revelam a proporção de uma separação em cada quatro casamentos, poder-se-ia questionar se esta instituição não estaria entrando em crise. De fato, a desintegração da família vem ocorrendo há mais de cem anos. Como fatores de influência para sua crise têm-se o individualismo, a revolução moral ou higienista, os novos papéis da mulher e o investimento afetivo nos filhos (LASCH, 1991).

Quando a mulher sai para as ruas e passa a receber por sua força de trabalho um salário tal como o homem, ela causa uma ruptura no seio da instituição família (VAITSMAN, 1994). Há uma nova assunção de valores e papéis sociais que exigem que o núcleo familiar produza uma ressignificação muito intensa para assimilá-la. A mulher deixa de ser parte do privado e passa a ser integrante do público. Essa troca de papéis produz lacunas na criação dos filhos; da mãe-educadora surge a mãe-trabalhadora e com isso todas as variáveis implícitas nela.

A família nesse contexto fica despreparada. Há uma insegurança grande por parte dos pais a respeito da educação dos filhos. A própria psicanálise surge como reforçadora da insegurança paterna quando tudo pode ser traduzido em traumas irreparáveis para a vida psíquica do indivíduo; não se sabe qual o melhor caminho para educar. A crença de que a família não mais satisfazia suas funções mais básicas favoreceu a expansão das escolas e dos serviços de bem-estar social (LASCH, 1991). A escola assume para si o cargo de educadora e disciplinadora das crianças (STEWART; GLYNN, 1978), pois a família já não consegue dar conta da transmissão de valores sempre em mudança da sociedade moderna (LASCH, 1991).

A discrepância entre a velocidade, a disseminação dos valores e a capacidade de interiorizá-los por parte do indivíduo torna-se um preditor destes problemas dentro da instituição família. Um exemplo desse conflito é o grau de investimento da família moderna nos filhos. Quando esta se tornou nuclear (pais e filhos), houve um superinvestimento afetivo dos primeiros em relação aos segundos. Os filhos passam a ser alvos dos amores paternos, merecendo todos os cuidados e proteções que estes últimos podem oferecer. Entretanto, ao lado deste superinvestimento afetivo há uma tendência a deixar de criar os filhos para o mundo, isto é, os pais tornam-se permissivos em sua forma de educar e não agem como incitadores da autonomia filial. Quando a prole percebe o superinvestimento afetivo de seus progenitores, ela utiliza o amor como moeda de troca; a ameaça de 
retirada do amor passa a ser uma forma de dominação daquela sobre estes (LASCH, 1991; STEWART; GLYNN, 1978). O aparente desapego dos filhos por seus pais na sociedade moderna reflete novas normas dentro da instituição família. Os pais ficam reféns do amor dos filhos, tornam-se permissivos em demasia. Estes últimos se desvinculam dos valores parentais, desejam buscar o mundo, transgredir as regras familiares que lhes foram ensinadas, formar seus próprios grupos, os quais certamente terão objetivos distintos de seus grupos parentais (ENRIQUEZ, 1994).

A tolerância dos pais para com sua prole origina as "famílias não-conflito" ou famílias "anormalmente anormais". Contudo, toda essa liberdade de expressão, esse respeito à individualidade pregados pela família moderna refletem certa anomia, uma perda de parâmetros para o comportamento social dos jovens que, sendo crias de "famílias normais", suicidam-se mais, drogam-se mais, colocando em dúvida se a abolição das normas institucionais da família são realmente limitadoras num sentido negativo (LASCH, 1991).

A ideologia individualista tensionou as relações entre os membros da família. Maridos e mulheres tentam, cada qual, resguardar seu próprio espaço, sua individualidade. O parceiro e os filhos representam uma ameaça ao desenvolvimento individual a qual deve ser minimizada com a valorização do privado. A "síndrome de estar juntos", característica dos casamentos baseados no amor romântico, deve ser abandonada em prol do crescimento de cada um. Os papéis sociais nesse contexto exercem um poder castrador sobre os membros da família. A felicidade e satisfação conjugais parecem depender da rejeição destes papéis (LASCH, 1991).

O amor romântico valorizado pelo casamento moderno é faca de dois gumes. Ao mesmo tempo em que gera expectativas a respeito do amor e da felicidade no matrimônio, provoca conflitos quando estas expectativas não são atingidas (ARAÚJO, 2002). Como forma de proteção à individualidade nascem os compromissos não-obrigatórios. Nestes os indivíduos são levados a respeitar o desempenho de papéis sociais a fim de mitigar as expectativas sobre a relação amorosa. Há a condenação do amor romântico como produtor de expectativas irrealistas e, portanto, de dissensões na vida conjugal (LASCH, 1991). A ideologia dos compromissos não-obrigatórios apresenta-se, então, como mais uma negação da instituição família, corrompendo os valores socialmente construídos sobre o casamento. A separação entre sexo e amor dentro da união conjugal pode ser vista como uma das características dos compromissos não-obrigatórios. Essa dicotomia foi introduzida pela ideologia higienista, tornando a sexualidade algo normatizado em favor da saúde (VAITSMAN, 1994). Desta forma, relações amorosas extraconjugais são legitimadas pelos médicos uma vez que o objetivo destes profissionais é apenas a manutenção da saúde; não há preocupação com as normas sociais reinantes no matrimônio, mas somente com os problemas biológicos e os custos decorrentes dos mesmos para o indivíduo e a sociedade. As relações abertas tomam força com esse respaldo institucional. A não-associação intrínseca entre amor e sexo abre espaço para a busca de prazer e satisfação pessoais sem 
culpas. A sociedade baseada nos compromissos não-obrigatórios, e nas relações abertas, torna-se menos hipócrita, posto que relações sexuais fora do casamento e desvinculadas de amor sempre existiram (GAIARSA, 1991).

A instituição família sofre rupturas com essa nova maneira dei encarar a própria sexualidade e a própria relação amorosa. Novas exigências são impostas pela sociedade moderna e muitos valores familiares são colocados em xeque. A família enquanto uma instituição social está sendo ressignificada. Não há um modelo de família na modernidade (VAITSMAN, 1994), o que há são famílias ou "fam-ilhas" como descreve Jablonski (1991), em que cada indivíduo vive junto, mas sem muitos contatos, sem a criação de vínculos sociais mais profundos. Talvez essa dificuldade de vinculação do indivíduo moderno se remeta ao problema dele em lidar consigo mesmo (ENRIQUEZ, 1992), de viver sempre na corda bamba do presente contínuo (BAUMAN, 1998), sem expectativas futuras, sem normas e papéis sociais que lhe forneçam diretrizes para seu convívio saudável dentro de uma sociedade cada vez mais instável.

\section{CONSIDERAÇÕes FINAIS}

As instituições sociais são de grande importância para a organização da vida social. Elas são grandes fomentadoras da ordem dentro das sociedades através de suas normas, valores e papéis. Saber como agir em uma gama de contextos sociais facilita a existência do indivíduo e suas relações com os demais.

São várias as instituições sociais, mas é sobre a instituição família que pesa o encargo de socializar o indivíduo dentro dos padrões socioculturais vigentes. Desta forma, a família representa uma instituição de extrema importância para a construção do caráter do indivíduo.

Mudanças no mundo atual colocam na berlinda a instituição família. Questões sobre como socializar uma criança adequadamente com valores sempre mutantes são de suma importância para a formação dos futuros cidadãos. O que será valorizado pela sociedade daqui a alguns anos pode não ter a mesma relevância que tem hoje, mas certamente terá sido o resultado do que está sendo feito agora.

A família sofre reformulações em suas normas institucionais. Importa saber quais os aspectos da sociedade que devem ser enfocados na socialização das crianças para que se tenha um meio de predizer com alguma probabilidade de acerto que sociedade ter-se-á futuramente.

No momento, tem-se uma família institucionalmente em modificação. Quais são seus valores, suas normas, suas características, suas principais funções? Como esta pensa agora? É possível que ela se acabe? Ou será apenas uma reformulação de seu pensamento institucional? Parece, contudo, que a instituição família passa por transformações em seus conteúdos muito mais do que em suas estruturas, e que ela muda o que é pensado, mas não sua forma de pensar. 


\section{REFERÊNCIAS}

ALBUQUERQUE, J. A. G. Instituição e poder: a análise concreta das relações de poder nas instituições. Rio de Janeiro: Graal, 1986.

ARAÚJO, M. F. Amor, casamento e sexualidade: velhas e novas configurações. Psicologia, Ciência e Profissão, Brasília, v. 2, p. 70-77, 2000.

BAUMAN, Z. O mal-estar da pós-modernidade. Rio de Janeiro: Zahar, 1998.

BERGER, P. L.; BERGER, B. O que é uma instituição social? In: FORACCHI; MARTINS, J. S. (Org.). Sociologia e sociedade: leituras de introdução à Sociologia. Rio de Janeiro: Livros Técnicos e Científicos, 1978. p. 193-199.

CASTORIADIS, C. A instituição imaginária da sociedade. Rio de Janeiro: Paz e Terra, 1982.

DOUGLAS, M. Como as instituições pensam. São Paulo: Edusp, 1998.

ENRIQUEZ, E. O vínculo grupal. In: LEVY, A; NICOLAI, A; ENRIQUEZ, E; DUBOST, J. (Org.). Psicossociologia: análise social e intervenção. Petrópolis: Vozes, 1994. p.56-69. 1990.

. Da horda ao Estado: Psicanálise do vínculo social. Rio de Janeiro: J. Zahar,

FÉRES-CARNEIRO, T. Separação: o doloroso processo de dissolução da conjugalidade. Estudos de Psicologia, Natal, v. 8, n. 3, 2003.

GAIARSA, J. A. Vida a dois. São Paulo: Siciliano, 1991.

JABLONSKI, B. Até que a vida nos separe. Rio de Janeiro: Agir, 1991

LASCH, C. Refúgio num mundo sem coração: a família: santuário ou instituição sitiada. Rio de Janeiro: Paz e Terra, 1991.

LOURAU, R. A análise institucional. Petrópolis: Vozes, 1996.

LOYOLA, M. A. ; QUINTEIRO, M. C. Estudos de população VIII - instituições e reprodução: estudo da atuação das instituições sociais no processo de reprodução humana. São Paulo: CEBRAP, 1982.

SÁ, C. P. Representações sociais: o conceito e estado atual da teoria. In: SPINK, M. J. (Org.). O conhecimento no cotidiano. São Paulo: Brasiliense, 1993. p. 19-45.

SCOTT, W. R. Institutions and organizations. London: Sage, 1996. 
SOUTO, C. A explicação sociológica: uma introdução à Sociologia. São Paulo: EPU, 1985.

STEWART, E. W.; GLYNN, J. A. Sociologia: uma introdução. São Paulo: Atlas, 1978.

VAITSMAN, J. Flexiveis e plurais: identidade, casamento e família em circunstâncias pósmodernas. Rio de Janeiro: Rocco, 1994.

Recebido em: maio de 2007

Aceito em: abril de 2008 